\title{
Attribution and Detection of anthropogenic Climate Change using a Backpropagation Neural Network
}

\author{
A. Walter* and C.-D. Schönwiese \\ Institut für Meteorologie und Geophysik der Johann Wolfgang Goethe-Universität \\ Frankfurt am Main
}

\begin{abstract}
The climate system can be regarded as a dynamic nonlinear system. Thus traditional linear statistical methods are not suited to describe the nonlinearities of this system which renders it necessary to find alternative statistical techniques to model those nonlinear properties.

In addition to an earlier paper on this subject [WALTER et al., 1998], the problem of attribution and detection of the observed climate change is addressed here using a nonlinear Backpropagation neural network (BPN). In addition to potential anthropogenic influences on climate $\left(\mathrm{CO}_{2}\right.$-equivalent concentrations, called greenhouse gases, GHG and $\mathrm{SO}_{2}$ emissions) natural influences on surface air temperature (variations of solar activity, volcanism and the El Niño/Southern Oscillation phenomenon) are integrated into the simulations as well.

It is shown that the adaptive BPN algorithm captures the dynamics of the climate system, i.e. global and area weighted mean temperature anomalies, to a great extent. However, free parameters of this network architecture have to be optimized in a time consuming trial-and-error process. The simulation quality obtained by the BPN exceeds the results of those from a linear model by far; the simulation quality on the global scale amounts to $84 \%$ explained variance. Additionally the results of the nonlinear algorithm are plausible in a physical sense, i.e. amplitude and time structure. Nevertheless they cover a broad range, e.g. the GHG-Signal on the global scale ranges from $0.37^{\circ} \mathrm{K}$ to $1.65^{\circ} \mathrm{K}$ warming for the time period 1856 - 1998. However the simulated amplitudes are situated within the discussed range [HOUGHTON et al., 2001]. Additionally the combined anthropogenic effect corresponds to the observed increase in temperature for the examined time period. In addition to that, the BPN succeeds with the detection of anthropogenic induced climate change on a high significance level. Therefore the concept of neural networks can be regarded as a suitable nonlinear statistical tool for modeling and diagnosing the climate system.
\end{abstract}

\section{Zusammenfassung}

Das Klimasystem kann als ein äußerst dynamisches nicht-lineares System angesehen werden. Aus diesem Grund erweisen sich traditionelle lineare statistische Methoden zur Beschreibung dieses Systems als nur bedingt geeignet, was erfordert, alternative statistische Modelle zu konzipieren, welche diese nichtlinearen Eigenschaften modellieren können. In Weiterführung einer früheren Arbeit zu diesem Thema [WALTER et al., 1998] wird hier ein nichtlineares Backpropagation Netzwerk (BPN) zur klimatologischen Signalanalyse und der Detektion des anthropogenen Treibhauseffektes eingesetzt.

Neben potentiellen anthropogenen Einflüssen auf das Klima $\left(\mathrm{CO}_{2}\right.$ - ̈̈quivalentkonzentrationen sog. Treibhausgase, engl. Greenhouse gases, GHG und $\mathrm{SO}_{2}$-Emissionen) werden auch natürliche Einflüsse auf die bodennahe Lufttemperatur (Variationen der solaren Aktivität, Vulkanismus und das El Niño/Southern Oscillation Phänomen) mit in die Simulation integriert. Es zeigt sich, daß das adaptive BPN in der Lage ist, die Dynamik des Klimasystems, d.h. Anomalien der globalen und regionalen bodennahen Mitteltemperatur, zu einem Großteil zu erfassen und zu modellieren. Freie Parameter der Netzwerkarchitektur müssen hierzu jedoch in einem zeitaufwendigen Prozeß optimiert werden.

*e-mail: A.Walter@meteor.uni-frankfurt.de 
Die mit dem BPN erzielte Simulationsgüte übertrifft jedoch die eines linearen Modell bei weitem; die Simulationsgüte auf der globalen Skala beträgt $84 \%$ erklärte Varianz. Zudem sind die erhaltenen Signalverläufe sowohl in ihrer Amplitude als auch in ihrer Zeitstruktur physikalisch plausibel. Jedoch decken diese Signale einen breiten Bereich ab; so liegt das GHG-Signal auf der globalen Skala in einem Beriech von $0.37^{\circ}$ bis $1.65^{\circ}$ Erwärmung. Die erzielten Signalstärken liegen jedoch in dem in der Literatur diskutierten Bereich [HOUGHTON et al., 2001]. Der kombinierte anthropogene Effekt entspricht weitestgehend dem beobachteten Anstieg der bodennahne Lufttemperatur im untersuchten Zeitraum $1856-1998$.

Weiterhin gelingt mit Hilfe der BPN-Architektur die Detektion des anthropogen verursachten Klimawandels auf einem hohen Signifikanzniveau. Aus diesen Gründen kann das Konzept der Neuronalen Netzwerke als ein alternatives, nichtlineares, statistisches Verfahren zur Modellierung und der Diagnose des Klimasystems angesehen werden.

\section{Introduction}

It is a widely accepted fact that most climate mechanisms are of a nonlinear nature [HOUGHTON et al., 2001]. Thus, traditional linear statistical models are not capable of describing the behavior of the climate system in its full complexitiy. Nonlinear Neural Network Models (NNM) provide a statistical solution to this problem.

NNM have their origin in studying the cognitive abilities of biological brain functions, i.e. how does the brain actually process infromation and how does it learn. A comprehensive overview of the wide range of this approach to time series analysis is compiled in [ANDERSON and ROSENFELD, 1986] and [RUMELHART and Mc CLELLAND, 1986].

Analogue to biological brains a typical NNM consists of a yet undefined number of simple processing units. The task of a (supervised learning) NNM is to 'learn' certain features of the data by using a training subset and to extrapolate these features on an unknown validation subset on which the performance of the NNM can be determined. Thereby internal parameters of the network architecture are adjusted according to a specific learning rule so that the network ideally captures all intrinsic data features.

The difference between NNM and and traditional statistical methods is the nonlinear character of NNM due to a nonlinear mapping function. This mapping function is commonly chosen out of the class sigmoid functions, because it has been shown [ADRIAN, 1926] that biological neurons respond to a stimulus in a sigmoidal fashion, i.e. no output until a certain threshold is exceeded, followed by a nearly linear input-output relation and saturation from a certain input level onward.

The conventional studies of climate change are either based on physical climate models, e.g. General Circulation Models (GCM) with a high computing and CPU time demand, or on statistical models such as Multiple Linear Regression (MLR), see for example [SHUMWAY and STOFFER, 2000], which allow only a limited exploration of the climate systems state.

Thus the nonlinear NNM fits in the gap between physical climate models with a high complexity nad linear statistical models by combining the advantages of both these models types, i.e. a rather quick nonlinear analysis technique.

Here a Backpropagation Network (BPN) [RUMELHART et al., 1986] is applied for simulating the climate system. Beside the simualtion of near-surface air temperature variations this work is aimed at the attribution and detection of anthropogenic climate change. Therefore, in a first step the isolation of cause-effect-relations is performed using the nonlinear BPN. After the successful statistical isolation of these relations detection studies based on the signal-to-noise ratio are performed. The 'detection variable' used is defined as a one-sided test for Gaussian distribution.

\section{Neural Network Models}

The spirit of neural network modeling is to use fully nonlinear functions and use a large number of terms so that model mismatch errors are not a concern. Instead of matching the architecture of the 
model to a problem, a model is used that can describe almost anything, and careful training of the model is used to constrain it to describe the data.

Here a Backpropagation Network (BPN) [RUMELHART et al., 1986] is chosen. The BPN is based on a supervised learning algortihm to ensure that the global minimum of a cost function is reached. However this approach bears a certain risk of overfitting. Thus, the data has to be seperated into a training and a validation subset. The actual 'learning' process of the network is performed on the training subset only whereas the validation subset serves as an independant reference for the simulation quality. This technique is called Cross-Validation [STONE, 1974]. When applying NNM to nonstationary time series, as in this approach here, the choice of the training subset has to ensure that the whole amplitude range of all forcing mechanisms concidered are covered. Otherwise the algorithm will fail if confronted with a high value in the validation process and such a high value never occured during the learning period. Therefore the training data can not be chosen continuously out of all data availabe. We used $75 \%$ of all data for training and the remaining for validation.

The input to a typical NNM is a vector of elements $\left(x_{k}\right)$, here the chosen climate forcings who represent global averages, see section 3. The index $k$ stands for the number of input units of the network, in the case considered here $k=5$ for the potential influences on global mean temperature, see again section 3 . These inputs are combined by a series of linear filters with weights $w_{j k}$, where $j$ represents the number of processing units, to give the inputs to the hidden units

$$
h_{j}=\sum_{k} w_{j k} x_{k} .
$$

The number of processing units used for the simulations is determined in terms of the networks performance on the validation sample, i.e. the number which gives the best results during validation. Because using too few/many processing units can easily lead to underfitting/overfitting problems, the simulation results are highly sensitive to a appropriate choice of the number of processing units. In the case of global mean temperature simulations the network architecture used was 5 input units (i.e. the potential influences on global temperature given in section 3), 23 processing units and 1 output unit (global temperature anomaly).

In the next processing step the nonlinearity is implemented. Thereby the inputs are passed through a layer of activation functions $g\left(h_{j}\right)$ to give the output of the hidden units

$$
X_{j}=g\left(h_{j}\right)=g\left(\sum_{k} w_{j k} x_{k}\right) .
$$

To retain the original analogy between NNM and learning mechanisms in the brain [ADRIAN, 1926], [AMIT, 1989] the activation functions are commonly chosen out of the class of sigmoid functions, additionally this choice will keep the model response bounded. We have chosen

$$
g(h)=\tanh (h)=\frac{e^{h}-e^{-h}}{e^{h}+e^{-h}} .
$$

The outputs from the hidden units then go through another layer of filters,

$$
H_{i}=\sum_{j} W_{i j} X_{j}=\sum_{j} W_{i j} g\left(\sum_{k} w_{j k} x_{k}\right),
$$

and are fed through another layer of activation functions to finally produce the outputs of the network

$$
Y=g\left(H_{i}\right)=g\left[\sum_{j} W_{i j} g\left(\sum_{k} w_{j k} x_{k}\right)\right],
$$

where $x_{k}$ are the chosen input variables $(k=5), w_{j k}$ are the weights from the $k$ input units to the $j$ processing units and the $W_{i j}$ are the weights from the processing units to the output unit. This model is very general. However, it has been shown that with one layer such a network can describe any continous function, and with two hidden layers, it can describe any function at all [CYBENKO, 1989]. 


\subsection{The Backpropagation Architecture}

The purpose of training a NNM is to find a set of coefficients which reduces the error between the set of outputs and the given test data $y\left(x_{k}\right)$. This is usually done by minimizing the least square error

$$
\begin{aligned}
\chi^{2} & =\frac{1}{2} \sum_{n} \sum_{i}\left[y\left(x_{k}\right)-Y\left(x_{k}\right)\right]^{2} \\
& =\frac{1}{2} \sum_{n} \sum_{i}\left[y\left(x_{k}\right)-g\left(\sum_{j} W_{i j} g\left(\sum_{k} w_{j k} x_{k}\right)\right)\right]^{2},
\end{aligned}
$$

where $n$ is the length of the time series. One way to reduce $\chi^{2}$ is gradient descent. The update step in the output weights can be found by differentiating

$$
\begin{aligned}
\Delta W_{i j} & =-\gamma \frac{\partial \chi^{2}}{\partial W_{i j}} \\
& =\gamma \sum_{n}\left[y\left(x_{k}\right)-Y\left(x_{k}\right)\right] g^{\prime}\left(H_{i}\right) X_{j} \\
& =\gamma \sum_{n} \Delta_{i} X_{j},
\end{aligned}
$$

defining

$$
\left.\Delta_{i}=\left[y_{(} x_{k}\right)-Y\left(x_{k}\right)\right] g^{\prime}\left(H_{i}\right) .
$$

In Eq. $7 \gamma$ is the socalled learning constant, a scale factor which controls how big the update step is and $g^{\prime}$ is the derivation of the sigmoidal activation function used, here $\tanh (x)$, see (Eq. 3 ).

The update in the input weights can be found using the chain rule:

$$
\begin{aligned}
\Delta w_{j k} & =-\gamma \frac{\partial \chi^{2}}{\partial w_{j k}} \\
& =\gamma \sum_{n} \sum_{i}\left[y\left(x_{k}\right)-Y\left(x_{k}\right)\right] g^{\prime}\left(H_{i}\right) W_{i j} g^{\prime}\left(h_{j}\right) x_{k} \\
& =\gamma \sum_{n} \sum_{i} \Delta_{i} W_{i j} g^{\prime}\left(h_{j}\right) x_{k} \\
& \equiv \gamma \sum_{x} \delta_{j} x_{k}
\end{aligned}
$$

defining

$$
\delta_{j}=g^{\prime}\left(h_{j}\right) \sum_{i} W_{i j} \Delta_{i} .
$$

The deltas for the input layer are found in terms of the deltas for the output layer by running them backwards through the networks $W_{i j}$ 's. Training a network by gradient descent, feeding the errors backwards through the network like this, is called error back propagation. This network architecture still bears the risk of being stuck in local minima on the $\chi^{2}$ hyperplane. To overcome this risk another NNM architecutre, the socalled Cauchy Mashine [SZU, 1986], which under certain conditions guarantees reaching the global minimum of a cost function, can be used, see e.g. [WALTER and SCHÖNWIESE, 2002] for a corresponding application to the one presented here. However, the results obtained using the Cauchy Mashine to the problem of anthropogenic climate change presented in this work, do not substantially differ from the results presented here, which gives us a certain confidence in the results of the BPN. 


\subsection{Uncertainties concerning the Backpropagation approach}

When using a BPN for simulation purposes certain 'features' of this approach have to be considered. The value of the learning constant has a significant effect on the networks performance. So to ensure that the network will settle to a solution the learning constant $\gamma$, see Eq. 7 and 9, should be asigned a propper value. Unfortunately no objective criterion to determine $\gamma$ exists [FREEMAN and SKAPURA, 1992], so a propper value for this parameter has to be determined in a time consuming trial-and-error approach.

A second uncertainty in the simulation is related to the gradient descent algortihm. The minimum the algorithm finds is dependant on the initial starting point on the $\chi^{2}$ hyperplane, i.e. since the BPN represents a nonlinear mapping function slightly different initial conditions can lead to large differences in the simulation results. To eliminate this kind of uncertainty the BPN was driven thirty times, each time only varying the initial starting point for the gradient algorithm on the error hyperplane. This led to different simulation results and furthermore to different results in the isolation of the climatological cause-effect-relations. In Fig. 3 only the averaged results are shown, whereas the range of our simulation results as well as the best estimate are summerized in Tab. 1.

\section{Data}

Annual globally averaged time series of observed climate variations for the period 1856-1998 have been used for the simulations. For the additional regional scale however a data set of 72 area weighted temperature averages for the time period 1892 - 1988 has been used. A high quality data set of mean global and mean hemispheric surface air temperature provided by [JONES et al., 1994] and updated regulary by [JONES, 1999a] served as the target function. The area weighted average time series used were derived from [JONES et al., 1994], [JONES, 1999a] respectively, the area design is according to [HANSEN and LEBEDEFF, 1987].

Anthropogenic greenhouse gas (GHG) forcing is represented in terms of $\mathrm{CO}_{2}$ equivalents also used by [HOUGHTON et al., 2001]. Because anthropogenic sulfate particles have only a atmospheric lifetime of a few days, this forcing may be directly proportional to the corresponding $\mathrm{SO}_{2}$ emissions. We used the updated $\mathrm{SO}_{2}$ emission data from [CHARLSON et al., 1992], the obtained signals are referred to as SU. Note that the BPN implicitly models both the direct and indirect effect of the SU forcing.

Explosive volcanism whose ejecta reach the stratosphere and form climate relevant sulfate aerosols is considered in terms of heating anomalies as provided by [GRIESER and SCHÖNWIESE, 1998].

The El Niño/Southern Oscillation phenomenon is part of natural climate variability. However, changes in the behaviour of El Niño could be part of the climate response to external, natural or anthropogenic, forcings. Thus, we used a reconstructed time series of the El Niño/Southern Oscillation phenomenon provided by [STAEGER, 1998] based on [JONES, 1999b] as additional forcing. This index is based on a SST reconstruction for the Gapalagos region by [DUNBAR et al., 1994], where anomalies of the ${ }^{18} \mathrm{O}$ isotope in corals were used. The linear correlation between the series by [JONES, 1999b] and by [STAEGER, 1998] for the time period 1866 - 1998 amounts to 0.96. Because of its global influence on near surface air temperature via teleconnections [PHILANDER, 1990] El Niño is implemented into the simulations as well. Finally the time series used to describe solar forcing is from [LEAN et al., 1995], [LEAN and RIND, 1999] respectively. Fig. 1 shows all the forcing mechanisms used for the simulations.

However, uncertainties in these forcing mechanisms remain and especially the level of scientific understanding concerning the SU forcing, i.e. the direct and indirect effect, is still very low [HOUGHTON et al., 2001]. 


\section{Preprocessing of the data}

Due to the fact that with the exception of global or hemispheric mean temperature, all spatial data sets represent variations in time and space a preanalysis using empirical orhogonal functions (EOF) [PREISENDORFER, 1988] was performed for the area weighted average time series of near surface temperatures. In this way one obtains 72 time-related principal components, ranked according to their explained variance, instead of 72 climate variable time series at 72 different areas. Thus the transformation can be written as

$$
z(x, t)=\sum_{j=1}^{m} \lambda_{j} E O F_{j}(x) P C_{j}(t),
$$

where $z(x, t)$ is the original space-time related data field, transformed into $m$ time-related principal components $P C_{j}(t)$ and a series of space-related principal components, called empirical orthogonal functions $\operatorname{EOF}_{j}(x)$. The factor $\lambda_{j}$ is called eigenvalue and quantifies the amount of variance of the related principal component existent in the original data. The $E O F_{j}$ provides the information about the weight of the corresponding $P C$ existent at the related point of space. The $P C_{j}(t)$ serve further on as the target function of our analysis. Fig. 2 provides a chart of explained variance vs. $P C$ number. The explained variance flattens after $P C_{4}$. Thus, in default of a objective criterion for how many $P C_{j}(t)$ 's to use here the first four principal components, which explain well over $50 \%$ of the total variance of the data field, have been selected as target functions for further investigations.

\section{$5 \quad$ Results and Interpretation}

Fig. 3 shows the simulation and the corresponding anthropogenic $(G H G, S U, G H G+S U)$ signals obtained using the BPN described above. After fitting the BPN, the full model is first used to model the combined effect of all forcings on temperatrure (simulation), while the model using each forcing individually, respectively combined in the $G H G+S U$ case, is then used to simulate the response of temperature to changes in that forcing alone (signals).

The simulation as well as the plotted signals are the average signals of thirty model runs to reduce the effect of falling into local minima of the cost function, see section 2.2 .

The globally averaged simulation quality amounts to $84 \%$ explained variance, a Multiple Linear Regression Model (MLR) driven by the same forcing time-series ends up with an explained variance of $75 \%$ on the global scale (results not shown) [WALTER, 2001]. Notice that the simulation shown in Fig. 3 (dashed line) is the result of a nonlinear superposition of all forcings mentioned in section 3.

The averaged signal amplitudes shown in Fig. 3 run up to $1.11^{\circ}$ for the GHG forcing, $-0.36^{\circ}$ for the sulfate aerosol forcing and $0.79^{\circ}$ for the combined anthropogenic forcing (GHG + SU). These amplitudes are very similar to findings carried out in recent General Circulation Models (GCM) simulations [STOTT et al., 2000], [TETT et al., 1999] and [HEGERL et al., 2000]. [STOTT et al., 2000] give a range of roughly $0.2 \mathrm{~K}$ /decade temperature increase for recent decades, which is very close to the findings of this work, $\approx 0.22 \mathrm{~K} /$ decade linear trend starting 1950 . The combined anthropogenic signal reflects the observed trend of $0.60^{\circ}$ [JONES, 1999a] for the analyzed time period rather well and is similar to that discused in [STOTT et al., 2000]. In addition to that the recent IPCC report [HOUGHTON et al., 2001] gives similar signal amplitudes for the above forcing mechanisms. A remarkable feature of the SU signal carried out is its time structure: a moderate cooling due to emissons of Sulfurdioxide until the 1940's followed by a rather pronounced cooling effect for the time period 1940 to 1970 and a rather weak colling from there on. This time structure is consistent with federal environmental legislation for most industrialized nations. Furthermore realistic simulations and signal amplitudes in a physical sense have been carried out for the northern and southern hemisphere as well [WALTER, 2001].

Additionally the BPN is able to simulate effects due to natural forcing mechanisms in a quite reasonable manner. Fig. 4 shows the simulated temperature anomalies following the 1917 La Niña and the $1982 \mathrm{El}$ Niño events. In both cases the stongest signals are found in the tropical Pacific: $-0.80 \mathrm{~K}$ 
colling following the La Niña and $0.50 \mathrm{~K}$ warming following the $1982 \mathrm{El}$ Niño. The simulated temperature pattern is in both cases consistent with dynamical aspects of ENSO, i.e. weakening/strengthening of the Aleutian pressure system and the known teleconnections between ENSO and the Indian Monsoon [PHILANDER, 1990], [HALPERT and ROPELEWSKI, 1992]. Aditionally the BPN captures the effects of the Mt. Pinatubo eruption on global mean temperature quite well, results not shown. The BPN simulates a cooling for the Tropics up to $-0.43 K$ in 1992 which is attributed to this eruption. Over North America and Central Asia cooling rates about $-0.32 \mathrm{~K},-0.21 \mathrm{~K}$ respectively are found [WALTER, 2001]. In [WALTER, 2001] it is shown, that the MLR tends to underestimate temperature effects of strong volcanic eruptions and overestimates the effects of medium eruptions when compared to the nonlinear BPN, which leads us to the conclusion, that explosive volcanism has a significant nonlinear effect on surface temperature.

To ensure that the BPN has captured all relevant mechanisms the residuals of the simulations have to be tested. This is usually done with testing for Gaussian distribution of the residuals e.g. Kolmogorov-Smirnov test. In case of a nonlinear BPN the residuals undergo the nonlinear transformations during the training of the network, therefore the residuals do not have to be gaussian distributed. An alternative statistical method for testing this kind of residual is the autocorrelation function [VON STORCH and ZWIERS, 1999]. Because the elements of white noise are independant it follows that their auto-correlation function $\rho(\tau)$ is

$$
\rho(\tau)=\left\{\begin{array}{lll}
1 & : & \tau=0 \\
0 & : & \tau \neq 0
\end{array},\right.
$$

where $\tau$ is the lag.

The autocorrelation function of the residual of the global simulation is shown in Fig. 5 (solid), also shown is the $95 \%$ confidence interval (dashed). The auto-correlation coefficient shows no significant deflection from zero. Thus it can be concluded that the BPN captured all relevant time structures and that the remaining residual can be treated as noise. The autocorrelation function of the residuals of the area weighted simulations reveal the same properties.

To obtain a useful 'detection variable' one has to look for a statisitcal relationship between the $P C_{j}(t)$ 's introduced in Section 4 and the forcings of interest. The observed spatio-temporal variations of the near surface temperature can be written as

$$
z(x, t)=S_{a n t h r}+S_{n a t}+\varepsilon,
$$

where $z(x, t)$ is the original data field, $S_{a n t h r}$ is the combined (GHG $+\mathrm{SU}$ ) anthropogenic signal, $S_{\text {nat }}$ are the natural signal, i.e. effects due to volcanims, ENSO and solar variations, and $\varepsilon$ is the unexplained residual. The signals and the residual in Eq. 13 have been transformed back into physical space after the BPN processing in EOF space. Note that the noise term in Eq. 13 is likely to be undersetimated, because it does not contain the roughly $50 \%$ variance not included in the first four $P C$ 's used in this simulation.

By testing the proportion between $S_{a n t h r}$ against $S_{n a t}+\varepsilon$ one obtains an assessment of the signalto-noise ratio, and in consequence of the confidence level of the detection of an anthropogenic induced climate change.

Using the ratio between the anthropogenic (GHG \& SU) forcing signal $S_{\text {anthr }}$ and the standard deviation of the remaining climate noise, it is possible to compute the space-time related probability $p$ of an anthropogenic induced climate change using the following equation

$$
P(\Theta \leq d|x, t|)=\operatorname{erf}\left(\frac{d(x, t)}{\sqrt{2}}\right),
$$

where $\Theta$ is a threshold value used for the computation of the $p$-confidence intervals and

$$
\operatorname{erf}(\mathrm{x})=\frac{2}{\sqrt{\pi}} \int_{0}^{x} \exp \left(-x^{2}\right) d x .
$$

$\operatorname{erf}(\mathrm{x})$ is the so-called error function which can be treated by numerical methods [PRESS et al., 1992]. 
Fig. 6 shows the results from this detection approach for a probability $p>90 \%$ that an anthropogenic (GHG \& SU) climate change has happened. Because of the fact that not only the signal but the signal-to-noise ratio decides about the detection of the anthropogenic signal the detection strategy introduced above succeeds at a high confidence level where the overall standard deviation of climate noise, i.e. natural signals plus residual see Eq. 13, is rather small. Because of a reduced year-to-year variability this is mainly the case for the tropics and oceanic region because of their large heat capacity and missing orographic effects on the atmospheric circulation.

However, the detection succeeds on a high confidence level for the mid-latitudes of the northern and southern hemisphere as well, this time because of enhanced signal amplitudes compared to those in the tropical regions. A linear MLR did not come up with similar results [WALTER, 2001] (results not shown), which is mainly due to the enhanced simulation quality of the BPN, and thus a reduced standard deviation of the remaining climate noise, see Eq. 14. Thus, regions with a low standard deviation $\varepsilon$ correspond to regions with a high probability of an anthropogenic climate change. In 35 out of 72 considered areas this probability exceeds $95 \%$ and in 13 out of 72 areas $p$ exceeds even $99 \%$, see Fig. 6.

\section{Conclusions}

In this work the possibilities of NNM for the purpose of attributing and detecting anthropogenic climate change have been studied. An NNM simulation represents nothing less than a nonlinear optimal fit. Therefore the results are highly sensitive to the choice of internal free parameters of the network architecture, e.g. learning constant $\gamma$ in Eq. 7 and Eq. 9, see section 2.2. However, if one carefully selects these parameters in order to prevent overfitting, the BPN provides a strong nonlinear statistical tool for climatological data analysis.

The results we obtained show a significant anthropogenic climate change for most regions of the globe, see again Fig. 6. On the global scale the best estimate of the combined effect of anthropogenic GHG and $\mathrm{SO}_{2}$ emissions into the atmosphere amounts to $0.79^{\circ}$ warming for the time period 1854 to 1998, see Fig. 3. Table 1 sumarizes the minimal, maximal and best estimate for the anthropogenic forcings (GHG, SU, GHG \& SU) obtained during thirty model runs.

On the aerea related scale, see Fig. 7, the BPN simulated a maximal anthropogenic $(\mathrm{GHG}+\mathrm{SU})$ effect over northern America $\left(0.98^{\circ} \mathrm{K}\right)$ and over Central Asia $\left(1.04^{\circ} \mathrm{K}, 1.08^{\circ} \mathrm{K}\right.$ respectively). These results are again reasonable in a physical sense because of the reduced heat capacity of these regions compared to those of the oceans. In the North Atlantic a rather weak warming of $\left(0.12^{\circ} \mathrm{K}\right)$ is simulated by the BPN. This effect is due to a enhanced downwelling of surface water [SMETHIE, 1993] and is is carried out by physical models as well, see again [HOUGHTON et al., 2001].

Thus, according to the results presented here, it is very likely that mankind is responsible for the observed increase in global mean surface temperature. 


\section{Figures}

\section{Figure captions}

Fig. 1 Forcing mechanisms used in the simulations. Units are: GHG forcing, $\mathrm{CO}_{2}$ equivalent concentrations $[\mathrm{ppm}] ; \mathrm{SO}_{2}$ forcing $\left[\mathrm{mg} / \mathrm{m}^{2}\right]$; ENSO forcing, normalized pressure anomalies [ $\left.\mathrm{hPa}\right]$; volcanic forcing $\left[\mathrm{W} / \mathrm{m}^{2}\right]$ and solar forcing $\left[\mathrm{W} / \mathrm{m}^{2}\right]$. See section 3 for details.

Fig. 2 Relative explained variance vs. $P C$ number. The explained variance flattens after $P C_{4}$

Fig. 3 Results of the global BPN simulation (dashed) and the corresponding GHG-signal (shortdashed), SU-signal (dashed-dotted) and the combined anthropogenic signal (dotted). Also shown are observed global temperature anomailes (solid) provided by [JONES et al., 1994], [JONES, 1999a] respectively.

Fig. 4 Modelled temperature anomalies $[K]$ due to 1917s La Niña (left) and 1982s El Niño (right). Notice the modelled features of a decreasing/increasing Aleutian pressure system and the teleconnections to the Indian monsoon.

Fig. 5 Autocorrelation function of the simulation residuals (solid). Also shown are $95 \%$ confidence intervalls.

Fig. 6 Probability $p>90 \%$ for an anthropogenic (combined GHG and SU effect) induced climate change.

Fig. 7 Signal amplitudes of the combined (GHG and SU) anthropogenic forcing in $[K]$. 

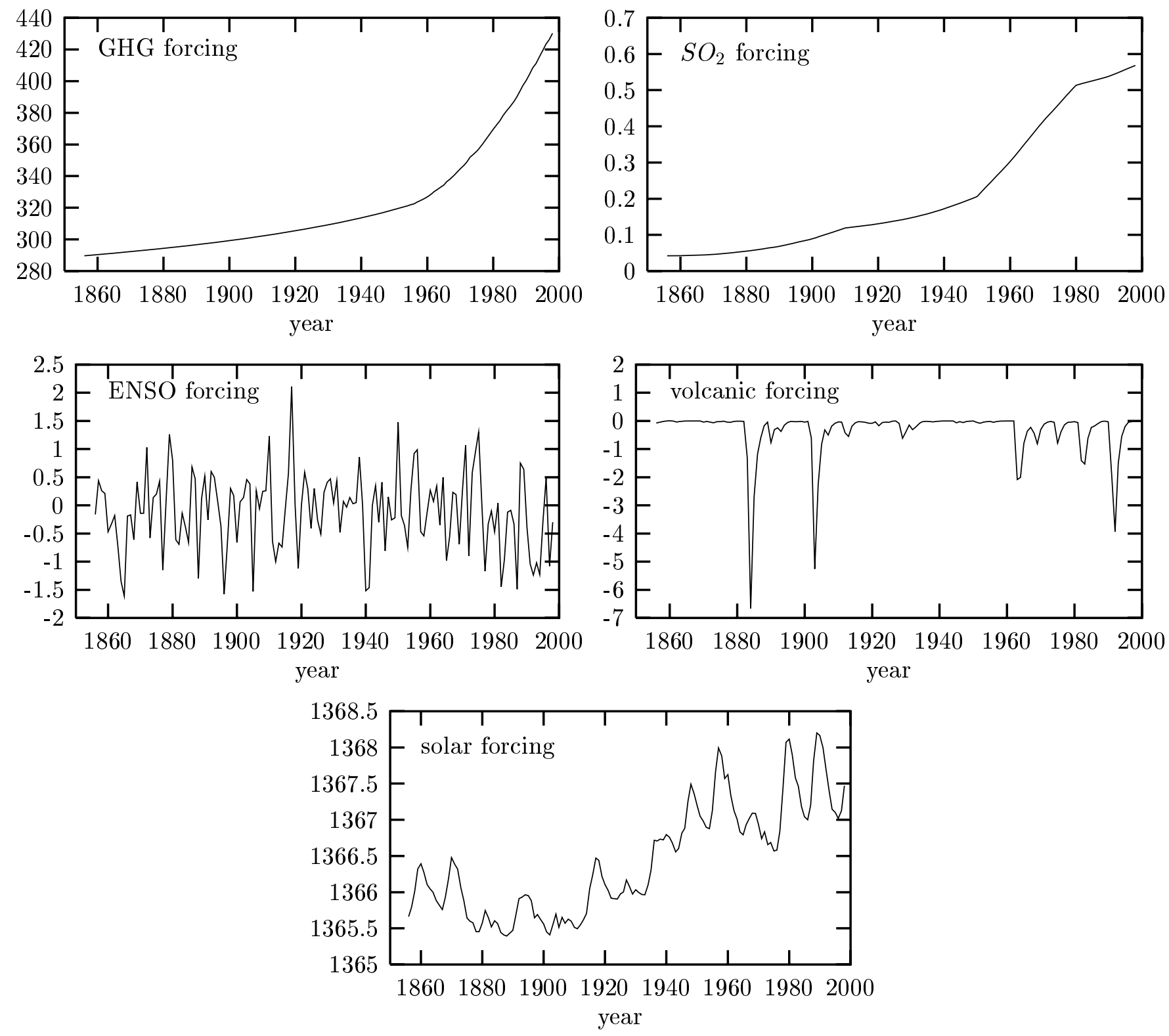


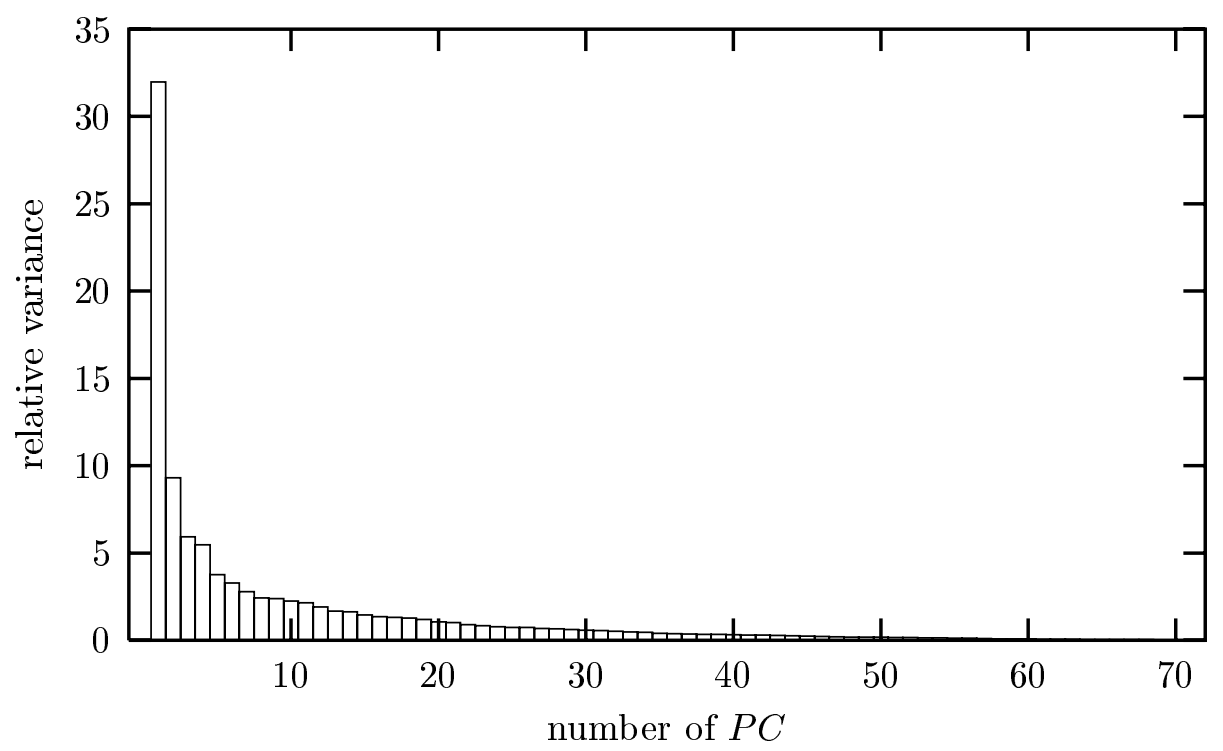




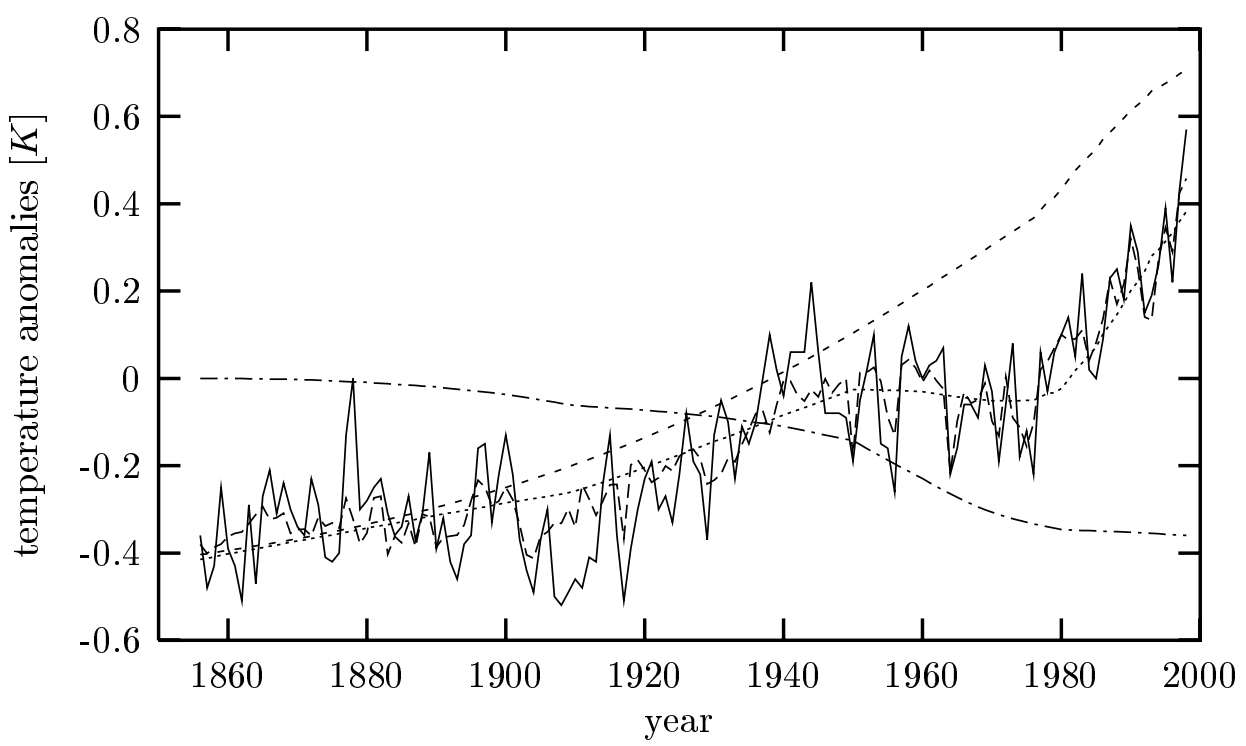



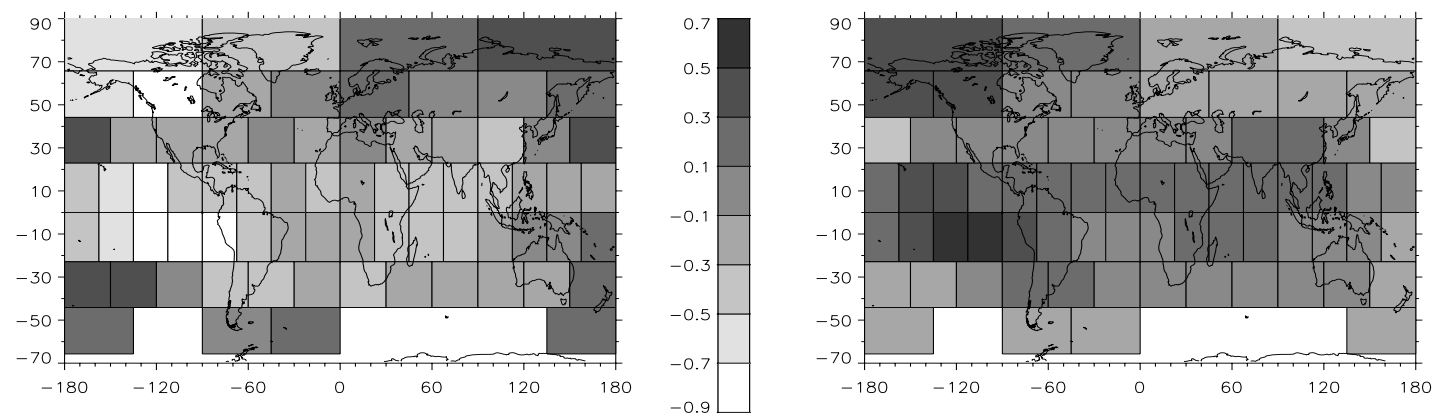

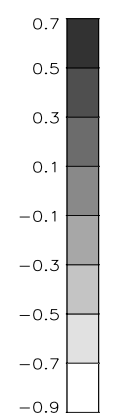




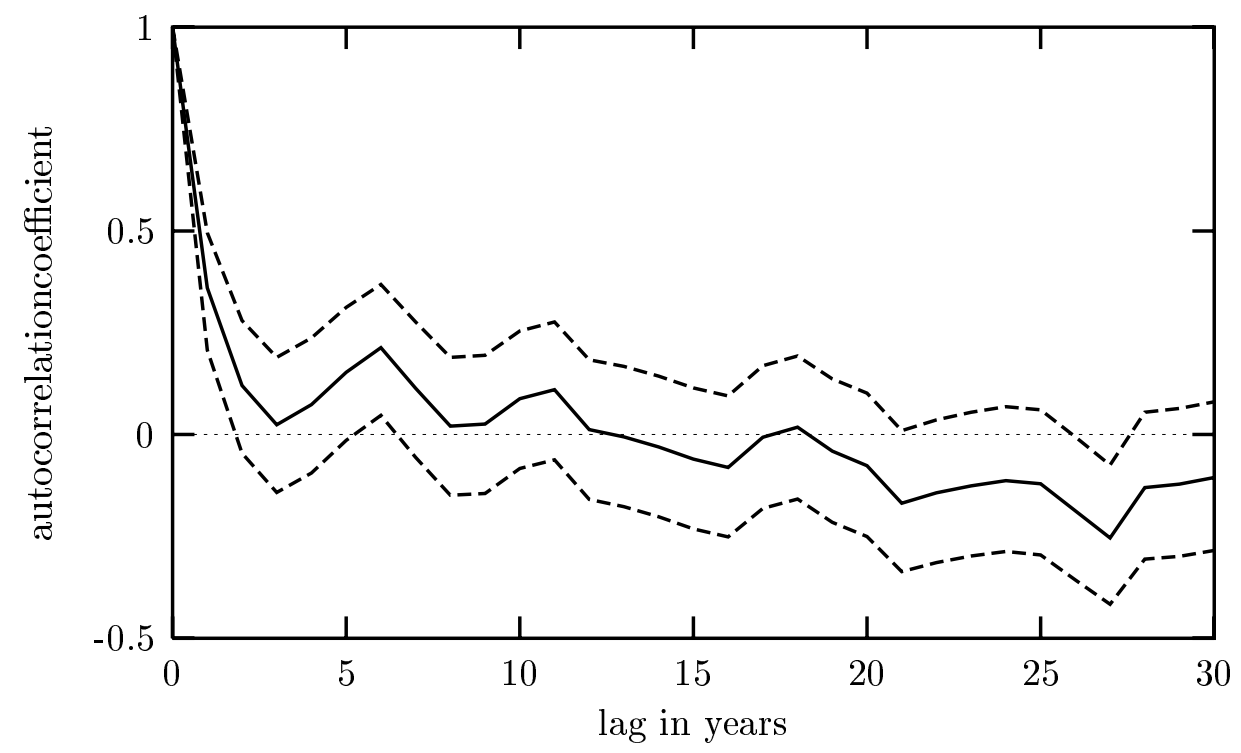



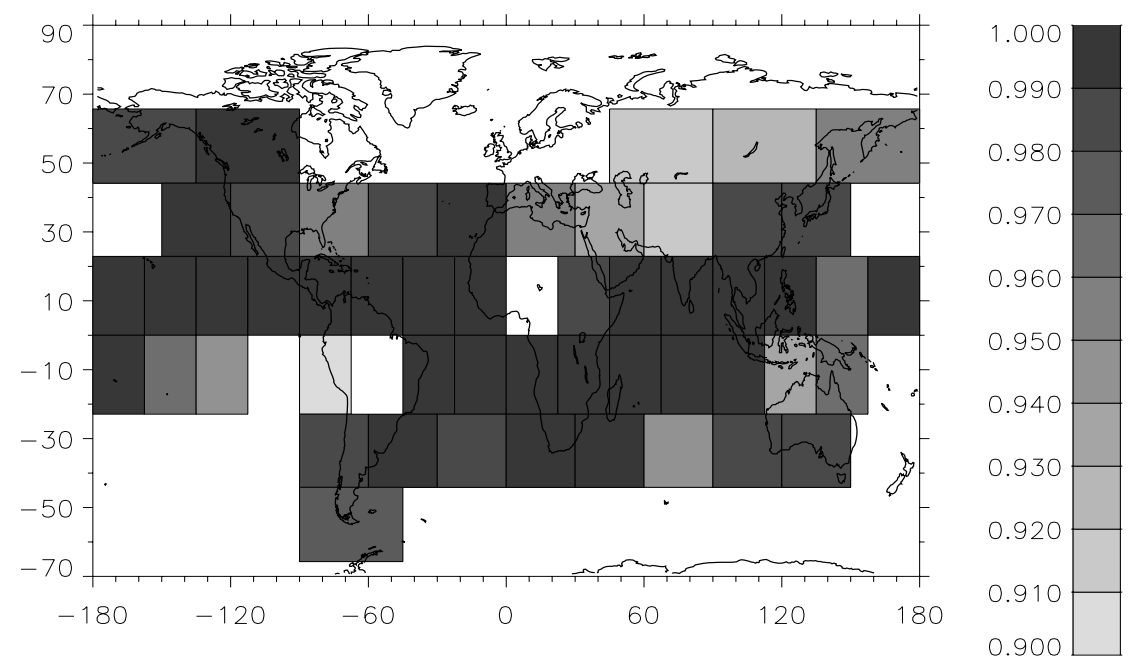

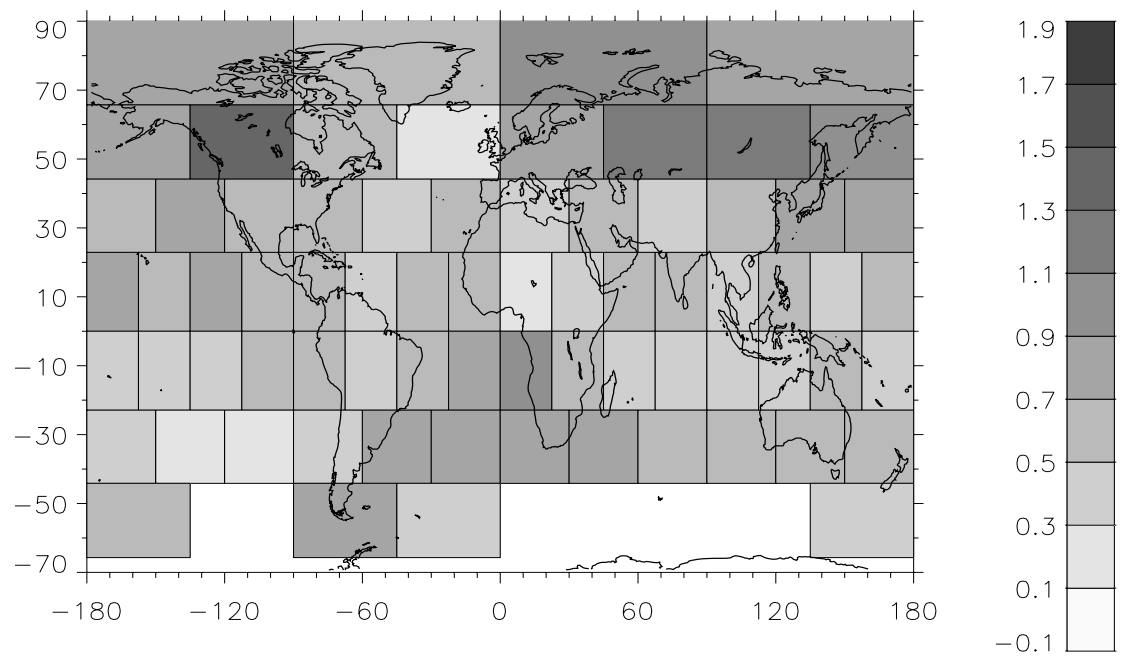


\begin{tabular}{|c||c|c|c|}
\hline Forcing & min. & max. & best estimate \\
\hline \hline GHG & $0.37^{\circ}$ & $1.65^{\circ}$ & $1.11^{\circ}$ \\
\hline SU & $-0.12^{\circ}$ & $-0.67^{\circ}$ & $-0.36^{\circ}$ \\
\hline GHG $+\mathrm{SU}$ & $0.46^{\circ}$ & $0.97^{\circ}$ & $0.79^{\circ}$ \\
\hline
\end{tabular}

Table 1: Signal amplitudes in $[K]$ of the minimal, maximal and best estimate for the signals obtained during thirty BPN simulations, global scale. The best estimate represents the average of these thirty simulation runs, see also Fig. 3. 


\section{References}

E.D. ADRIAN. The impulses produced by sensory nerve endings: Part I. J. Physiol., 61:49-72, 1926.

D.J. AMIT. Modeling brain function. The world of attractor neural networks. Cambridge University Press, Cambridge, 1989. 528 pages.

J.A. ANDERSON and E. ROSENFELD, editors. Neurocomputing. Foundations of Research. MIT Press, Cambridge, MA., 1986. 729 pages.

R.J. CHARLSON, S.E. SCHWARTZ, J.M. HALES, R.D. CESS, J.A. COAKLEY Jr., J.E. HANSEN, and D.J. HOFFMAN. Climate Forcing by Anthropogenic Aerosols. Science, 255:423-430, 1992.

G. CYBENKO. Approximation by Superpositions of a Sigmoidal Function. Mathematics of Control, Signal and Systems, 2:303-314, 1989.

R.B. DUNBAR, G.M. WELlington, M.W. COLGAN, and P.W. GLYNN. Eastern Pacific Sea Surface Temperatures since 1600 A.D.: The d180 Record of Climate Variability in Galapagos Corals. Paleoceanography, 9:291-315, 1994.

J.A. FREEMAN and D.M. SKAPURA. Neural Networks. Algorithms, Applications and Programming Techniques. Addison-Wesley, Reading, MA., 1992. 401 pages.

J. GRIESER and C.-D. SCHÖNWIESE. Parametrization of Spatio-temporal Patterns of Volcanic Aerosol induced Stratospheric optical Depth and its Climate Radiative Forcing. Atmósphera, 12: 111-133, 1998.

M.S. HALPERT and C.F. ROPELEWSKI. Surface Temperature Patterns Associated with the Southern Oscillation. Journal of Climate, 5:577-593, 1992.

J. HANSEN and S. LEBEDEFF. Global trends of measured surface air temperature. J. Geophys. Res., 92:13345-13372, 1987.

G.C. HEGERL, P.A. STOTT, M.R. ALLEN, J.F.B. MITCHELL, S.F.B. TETT, and U. CUBASCH. Optimal detection and attribution of climate change: sensitivity of results to climate model differences. Clim. Dyn., 16:737-754, 2000.

J.T. HOUGHTON, Y. DING, D.J. GRIGGS, M. NOGUER, P.J. van der LINDEN, X. DAI, K. MASKELL, and C.A. JOHNSON. Climate Change 2001. The Scientific Basis. Cambridge University Press, Cambridge, 2001. 881 pages.

P.D. JONES. http://www. cru.uea.ac.uk:80/cru/data/temperat.htm, 1999a.

P.D. JONES. http://www.cru.uea.ac.uk/cru/data/soi.htm, 1999b.

P.D. JONES, T. M. L. WIGLEY, and K. R. BRIFFA. Global and hemispheric temperature anomalies - land and marine instrumental records. In T. A. Boden, D. P. Kaiser, R. J. Sepanski, and F. W. Stoss, editors, Trends '93: A Compendium of Data on Global Climatic Change, pages $603-608$. 1994.

J. LEAN, J. BEER, and R. BRADLEY. Reconstruction of Solar Irradiance since 1610: Implications for Climate Change. Geophysical Research Letters, 22:3195-3198, 1995.

J. LEAN and D. RIND. Climate Forcing by Changing Solar Radiation. Journal of Climate, 11: 3069-3094, 1999.

S.G. PHILANDER. El Niño, La Niña and the Southern Oscillation. volume 46 of International Geophysics Series. Academic Press, San Diego, New York, 1990. 293 pages. 
R. PREISENDORFER. Principal Component Analysis in Meteorology and Oceanography. Developmets in Atmospheric Science 17. Elsevier, Amsterdam, 1988. 425 pages.

W.H. PRESS, S.A. TEUKOLSKY, W.T. VETTERLING, and B.P. FLANNERY. Numerical Recipies. Cambridge University Press, Cambridge, 1992. 934 pages.

D.E. RUMELHART, G.E. HINTON, and R.J. WILLIAMS. Learning Internal Representations by Error Propagation. In Parallel Distributed Processing: Explorations in the Microstructure of Cognition, pages 318-362. MIT Press, Cambridge, MA., 1986.

D.E. RUMELHART and J.L. Mc CLELLAND. Parallel Distributed Processing: Explorations in the Microstructure of Cognition. MIT Press, Cambridge, MA., 1986. 2 Vols., 1158 pages.

R.H. SHUMWAY and D.S. STOFFER. Time Series Analysis and Its Applications. Springer Texts In Statistics. Springer, New York, NY., 2000. 549 pages.

W.M. SMETHIE. Tracing the thermohaline circulation in the western North Atlantic using chlorflourmethanes. Prog. Oceanogr., 31:51-99, 1993.

T. STAEGER. Statistische Analyse des ENSO- und Vulkanismus-Signals in Klima-Zeitreihen. Master's thesis, Johann Wolfgang Goethe-Universität, Frankfurt, 1998. 84 pages.

M. STONE. Cross-validatory Choice and Assessments of Statistical Predictors. Journal of the Royal Statistical Society, B36:111-147, 1974.

P.A. STOTT, S.F.B. TETT, G.S. JONES, M.R. AlLEN, J.F.B. MITCHELL, and G.J. JENKINS. External Control of 20th Century Temperature by Natural and Anthropogenic Forcings. Science, 290:2133-2137, 2000.

H. SZU. Fast simulated annealing. In J.S. Denker, editor, Neural Networks for Computing, pages 420-425. American Institute of Physics, New York, NY., 1986.

S.F.B. TETT, P.A. STOTT, M.R. AllEN, W.J. INGRAM, and J.F.B. MITCHELL. Causes of twentieth-century temperature change near the Earth's surface. Nature, 399:695-572, 1999.

H. VON STORCH and F.W. ZWIERS. Statistical Analysis in Climate Research. Cambridge University Press, Cambridge, 1999. 484 pages.

A. WALTER. Zur Anwendung neuronaler Netze in der Klimatologie. PhD thesis, Johann Wolfgang Goethe-Universität, Frankfurt, 2001. Berichte des Deutschen Wetterdienstes No. 218, 168 pages.

A. WALTER, M. DENHARD, and C.-D. SCHÖNWIESE. Simulation of Global and Hemispheric Temperature Variations and Signal Detection Studies Using Neural Networks. Meteorol. Z., N.F.7: $171-180,1998$.

A. WALTER and C.-D. SCHÖNWIESE. A Fast Simulated Annealing Schedule implemented on a Cauchy Machine as a Nonlinear Statistical Tool for the Attribution and Detection of Anthopogenic Climate Change. Theoretical and Applied Climatology, 2002. in prep. 